isolated. This was not, however, accompanied by an increase in the symptoms or signs of genital mycotic infection. In this department the proportion of patients taking oral contraceptives has nearly doubled in the past four years, and it may be that a general increase in the use of these agents has led to an increase in the occurrence of yeasts in the female genital tract rather than to any specific effect in the production of symptoms or signs of infection.

In the present series $\mathrm{Tr}$. vaginalis infestation was common, occurring in $18 \%$ of women; this is more than three times the rate reported from an antenatal clinic in the same part of London (Hurley et al., 1972). Tr. vaginalis is sexually transmissible (King and Nicol, 1969), and no doubt the high levels found in the present patients were a reflection of their sexual activity. The ratio of yeast infection to $T r$. vaganilis infestation was $1 \cdot 5: 1$, comparable with the ratio of $2: 1$ reported from another department of venereology in London (Catterall, 1971). Simultaneous infection with yeasts and $T r$. vaginalis is uncommon and was found in only 11 patients; the optimal environmental conditions for the organisms may well be quite different (Müller et al., 1967).

Like $T r$. vaginalis, yeasts are often harboured without symptoms. In the present study $27 \%$ of the patients with $\mathrm{Tr}$. vaginalis and $19 \%$ of the patients with yeasts were asymptomatic. Many factors are recognized which lead to an increase in yeasts in the vaginal microflora (Catterall, 1966), but why some patients develop clinical symptoms and signs of yeast infection while others do not is uncertain. Local reaction to the organisms, possibly of an allergic nature (Holti, 1966), is presumably responsible but its nature is incompletely understood. Of the supposedly characteristic symptoms of yeast infection pruritus was found the most often, in $50 \%$ of these patients; the complaint of vaginal discharge was so commonly made by all patients as not to be helpful in clinical diagnosis. Pruritus, however, was also complained of by $23 \%$ of the patients with trichomoniasis and $19^{\circ} \%$ of those with no evidence of infection. Vulvovaginitis with or without the formation of plaques was certainly a more characteristic sign of yeast infection, being present in $38 \%$ of cases; it was observed in only $14 \%$ of patients with trichomoniasis and $7 \%$ of those with negative tests.

Nevertheless, it must be concluded that a clinical diagnosis of vaginal mycosis cannot be made with accuracy, the supposedly characteristic symptoms and signs being present in other conditions. Only a positive identification of yeasts by cultural methods will enable the clinical situation to be interpreted. This is particularly so in patients where multiple infections are not unusual, as in the present series; one-third of these patients harbouring yeasts had other genital infections as well.

When should vaginal yeast infection be treated ? It is sometimes suggested that patients who are carrying yeasts without symptoms do not require treatment, which should be reserved for those with clinical evidence of infection. It is shown here, however, that clinical assessment of vaginal mycosis presents difficulties, particularly when multiple infections are present. In addition there is no way of predicting which women with asymptomatic yeast infections may later develop a clinical mycosis. Finally, about $10 \%$ of men who have intercourse with women with yeast infection develop balanoposthitis. For these reasons we think that when the diagnosis of yeast infection, based on the positive identification of a pathogenic yeast in the laboratory, has been made the patient should be treated, irrespective of whether symptoms or signs of vaginal mycosis are present. Cultural methods as well as being invaluable for precision in diagnosis can then also be used in assessing the results of such treatment.

We are grateful to Professor H. I. Winner for his advice during this undertaking.

\section{References}

Anyon, C. P., Desmond, F. B., and Eastcott, D. F. (1971). New Zealand Medical fournal, 73, 9 .

Catterall, R. D. (1966). Lancet, 2, 830

Catterall, R. D. (1971). British fournal of Venereal Diseases, 47, 45.

Denny, M. J., and Partridge, B. M. (1968). Fournal of Clinical Pathology, $21,383$.

Diddle, A. W., Gardner, W. H., Williamson, P. J., and O'Connor, K. A. (1969). Obstetrics and Gynecology, 34, 373.

Eddie, D. A. S. (1968). Fournal of Medical Microbiology, 1, 153.

Holti, G. (1966). In Symposium of Candida Infections, ed. H. I. Winner and R. Hurley, p. 73. Edinburgh, Livingstone.

Hurley, R., Leask, B. G. S., Faktor, J. A., and de Fonseka, C. I. (1972). urley, R., Leas

In press.
King, A., and Nicol, C. S. (1969). Venereal Diseases, 2nd. edn, p. 245. London, Baillière, Tindall, and Cassell.
Lond

Lodder, J. (1970). The Yeasts: a Taxonomic Study. Amsterdam, North Holland Publishing.

Morris, C. A., and Morris, D. F. (1969). British Medical fournal, 1, 319. Müller, W. A., Holtorff, J., and Blaschke-Hellmessen, R. (1967). Archiv für Hygiene und Bakteriologie, 151, 610.

Porter, P. S., and Lyle, J. S. (1966). Archives of Dermatology, 93, 402.

Rohatiner, J. J., and Grimble, A. (1970). Fournal of Obstetrics and Gynaecology, of the British Commonwealth, 77, 1013.

Timonen, S., Salvo, O. P., Meyer, B., and Haapoja, H. (1966). Acta Obstetricia et Gynecologica Scandinavica, 45, 232.

Walsh, H., Hildebrandt, R. J., and Prystowsky, H. (1968). American fournal of Obstetrics and Gynecology, 101, 991.

Wilkey, I. S. (1967). Australian and New Zealand fournal of Obstetrics and Gynaecology, 7,237.

Yaffee, H. S., and Grots, I. (1965). New England fournal of Medicine, 272, 647 .

\title{
Pulmonary Contusion in Children due to Rubber Bullet Injuries
}

\section{J. SHAW}

British Medical fournal, 1972, 4, 764-766

\section{Summary}

Three cases of pulmonary contusion occurred in children as a result of injuries from "rubber bullets." Radiological changes were evident soon after the injury, and in one case these persisted for two months. Symptoms disappeared quickly in all three cases.

Royal Belfast Hospital for Sick Children, Belfast Northern Ireland

J. SHAW, M.B., F.R.C.s., Senior Surgical Registrar (Present appointment: Consultant Surgeon, Ulster Hospital, Dundonald, Belfast, Northern Ireland)

\section{Introduction}

A review of all known serious injuries due to the impact of rubber bullets sustained during the present civil unrest in Northern Ireland is to be published elsewhere (Millar, 1972). Three cases of closed chest injury in children are reported here more fully because of the unusual features they present.

The Missile. - The missile is a bullet made of solid rubber measuring $15 \mathrm{~cm}$ by $3.8 \mathrm{~cm}$ and tapering to a blunt point at one end (Fig. 1). It weighs $150 \mathrm{~g}$, and is fired from a riot gun with a muzzle velocity of $116.5 \mathrm{metres} / \mathrm{sec}$. It is used for riot control and is fired into a hostile crowd from a range of more than $30 \mathrm{yd}(27.4 \mathrm{~m})$. It is intended that it should have the wounding characteristics of a baton and inflict no more than painful 


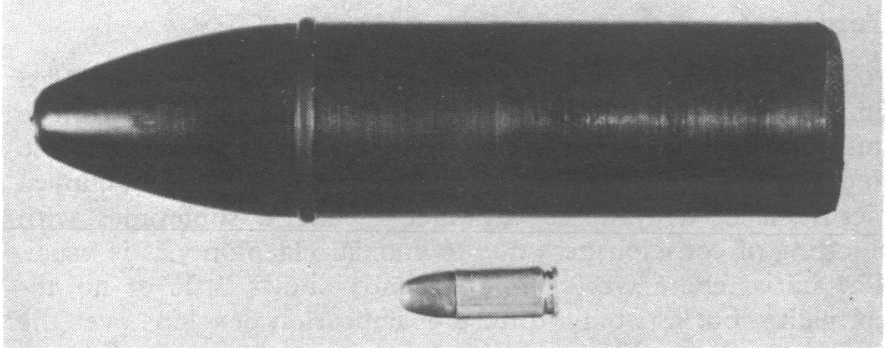

FIG. 1-Rubber bullet measuring $15 \mathrm{~cm}$ by $3.8 \mathrm{~cm}$, weight $150 \mathrm{~g}$, compared with $9 \mathrm{~mm}$ pistol cartridge.

bruising, but from time to time more serious injuries are sustained.

\section{Case 1}

A boy aged $9 \frac{1}{2}$ years was hit on the right upper chest during a civil disturbance and was admitted to hospital within an hour. On admission he was dyspnoeic and had an irritating hacking cough productive of pink frothy sputum streaked with blood. He was not cyanosed. His respiratory rate was $26 / \mathrm{min}$, pulse rate $100 / \mathrm{min}$ and blood pressure $115 / 75 \mathrm{~mm} \mathrm{Hg}$. There was a bruise on the right upper chest below the clavicle. Examination of the lungs showed diminished air entry all over the right lung field, but no adventitious sounds were heard.

A chest $x$-ray picture showed an extensive opacity in the right lung field corresponding with the position of the bruise on the chest wall (Fig. 2). There was no rib fracture.

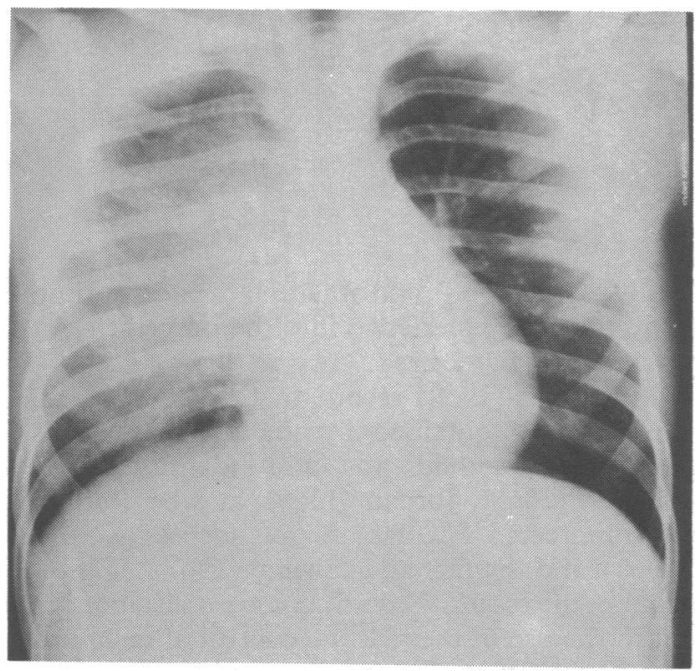

FIG. 2-Case 1. Chest $x$-ray picture on admission showing extensive opacity in right lung field corresponding with position of bruise.

Arterial $\mathrm{Po}_{2}$ was 64, $\mathrm{PcO}_{2}$ was 61, and $\mathrm{pH}$ was $7 \cdot 27$ (breathing air). He was treated with oxygen via a nasal catheter and was given ampicillin. By the following morning he was symptom free and running about the ward. He was discharged five days after injury, by which time the chest films showed some clearing of the original opacity. Follow-up has proved difficult in the present circumstances, but he did attend once two months after injury. He remained symptom free, but there was still residual shadowing in the right mid zone. Further attempts to see him again have failed.

\section{Case 2}

A boy aged 11 years was hit in the left lower chest posteriorly and was admitted to hospital within an hour of injury. He stated that immediately after being hit blood "just came straight up" out of his mouth. He was dyspnoeic with a respiratory rate of $26 / \mathrm{min}$. He had a hacking, distressing cough productive of a little frothy pink sputum and occasional frank haemoptysis. There was a bruise 3 in by 1 in $(7.6 \times 2.5 \mathrm{~cm})$ over the left 7th-10th ribs 2 in $(5.1 \mathrm{~cm})$ posterior to the posterior axillary line. Clinical examination of the lungs showed diminished air entry at the left base with occasional rhonchi.

A chest $x$-ray picture (Fig. 3) showed an opacity at the left base with obliteration of the outline of the left dome of the diaphragm,

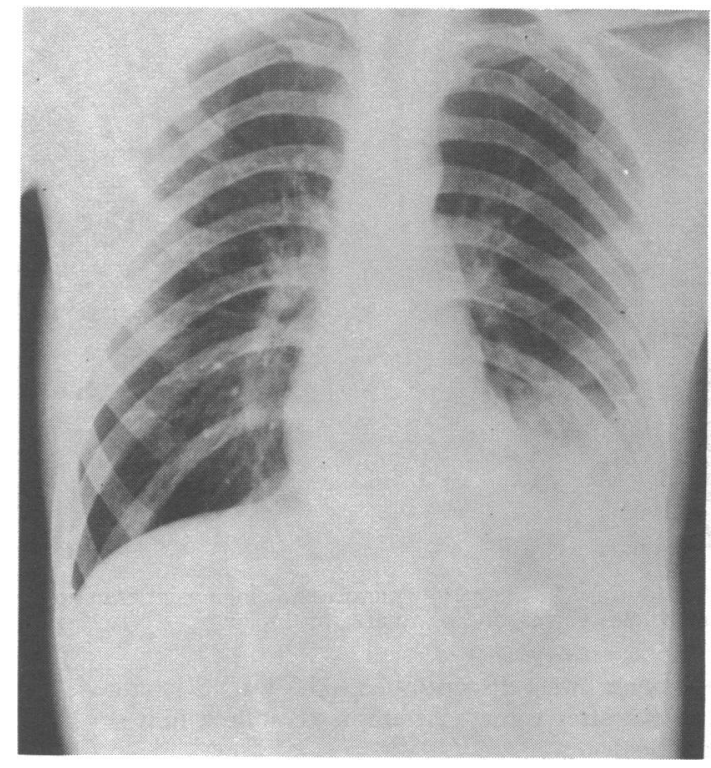

FIG. 3-Case 2. Chest $x$-ray picture on admission showing opacity at left base with obliteration of outline of left dome of diaphragm.

but a clearly defined left heart border localizing the opacity to the lower segment of the left lower lobe. The rib cage was intact.

Arterial $\mathrm{Po}_{2}$ was 76 and $\mathrm{pH}$ was 7.37 (breathing air). He was treated with oxygen by a plastic face mask and was given ampicillin. Within a few hours his respiratory distress had improved, and after the first day there was no haemoptysis. He was discharged four days after the injury symptom free. Follow-up has also proved difficult in his case though he did appear once four weeks after injury. He was symptom free, but chest $x$-ray examination showed some residual opacity at the left base.

\section{Case 3}

A boy aged 14 years was hit over the sternum by a rubber bullet, which he stated was fired from about a 10-yd (9-m) range. On admission to hospital he was dyspnoeic and was coughing up bright red frothy sputum. There was a bruise over the sternum (Fig. 4), and rales were heard over both lung fields. A chest $x$-ray

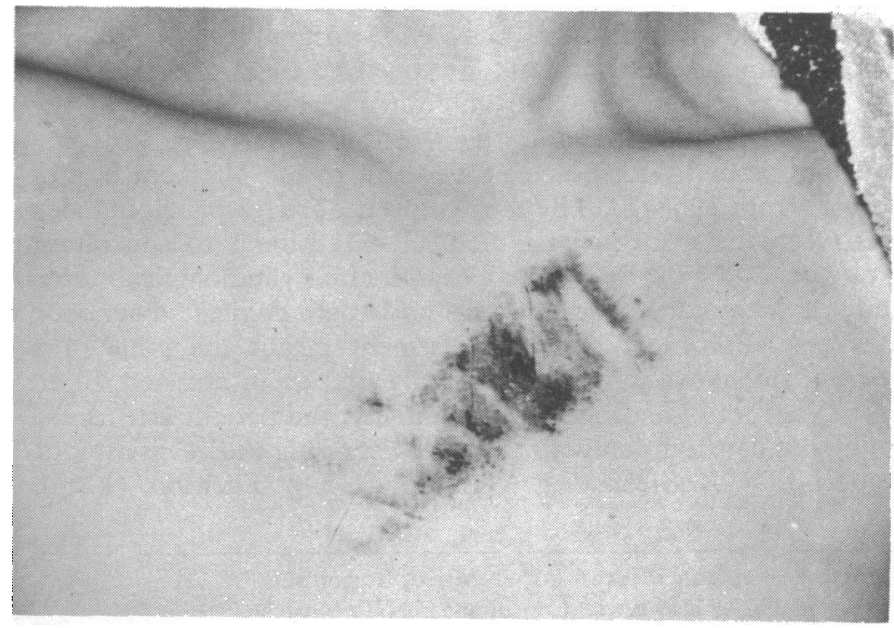

Fr. 4-Case 3. Appearance on admission, showing bruising of chest wall. 
picture showed opacities in both lung fields corresponding to the area of impact of the bullet (Fig. 5). There was no fracture of ribs or sternum. Arterial $\mathrm{PO}_{2}$ was $45, \mathrm{PCO}_{2}$ was 37 , and $\mathrm{pH}$ was $7 \cdot 32$ (breathing air). He was treated with $40 \%$ oxygen on which the $\mathrm{Po}_{2}$ rose to 115 . By the morning after injury he was much improved

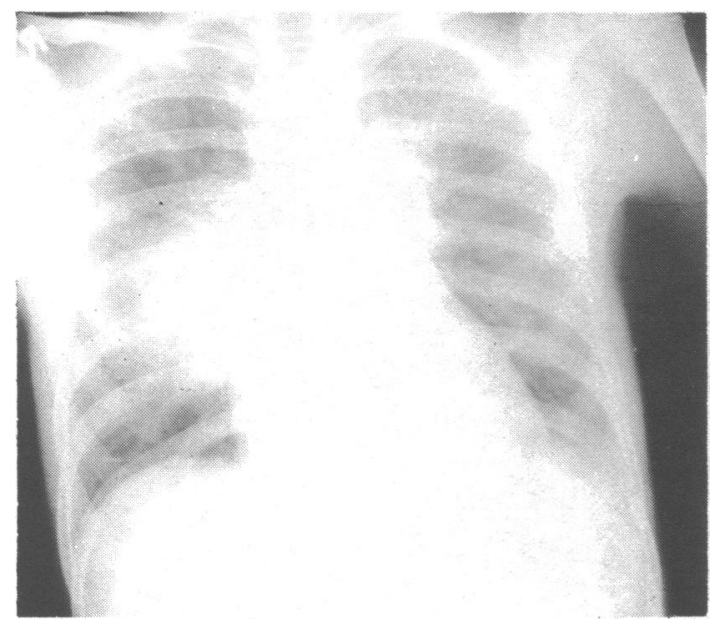

FIG. 5-Case 3. Chest $x$-ray picture showing opacities in both lung fields corresponding to area of impact.

and the oxygen was discontinued. He was discharged symptomfree four days after injury. Attempts to follow him up have so far proved fruitless.

\section{Comment}

"Contusion of the lung," "traumatic pneumonia," and "blast lung" are all terms used to describe a more or less diffuse infiltration of the alveoli and interstitial tissue by blood, and also to describe localized pulmonary haematomas. The usual clinical picture is of a cyanosed, dyspnoeic patient, sometimes with clouding of consciousness due to anoxia. Haemoptysis is usual. The initial chest $x$-ray film frequently shows little or no abnormality, but a patchy, diffuse opacification develops over the next day or two. The condition resembles lobar pneumonia in that it is completely resolvable within two to three weeks (London, 1967).

In the present cases the clinical features were a little unusual in that none was cyanosed. Haemoptysis occurred very soon after injury, and in Case 2 "immediately." The pulmonary opacity corresponded very closely with the area of impact of the bullet, probably due to the yielding characteristics of the child's chest. Each child showed a remarkably rapid symptomatic improvement within a matter of hours, but without corresponding radiological improvement. Radiographical changes were still present in the two patients who were seen for review, in one case after two months and in the other after four weeks.

I am indebted to Mr. W. Cochran and to Mr. T. B. Smiley for permission to report on the cases admitted under their care.

\section{References}

London, P. S. (1967). A Practical Guide to the Care of the Injured, p. 626 London, Livingstone. Millar, R. M. (1972), To be published.

\section{Voluntary Visitors to the Elderly Deaf}

\section{DENNIS CLARK}

British Medical fournal, 1972, 4, 766-768

\section{Introduction}

The prevalence of deafness in age groups has been the subject of investigations by Beasley (1940), Wilkins (1949), and Gregory (1964) on which other authorities such as Gunnar Liden (1968) depend. By applying these authors' figures to the 1961 local census a rough estimate of the numbers of elderly deaf in the Weston-super-Mare district was made in 1968. It was found that the population over the age of 65 years was $20.6 \%$ (1971, $20.8 \%$ ), almost double the national average, and the expected number of elderly deaf in the district would be 1,550 with an equal number in the surrounding districts of Axbridge, Long Ashton, and Burnham-on-Sea who normally attended the Weston-super-Mare hospitals for specialist medical attention.

This paper describes the voluntary visiting service to the elderly deaf who attended the Weston-super-Mare Hospital and were issued with hearing aids through the National Health Service from 1968-70. The normal procedure for providing aids was reference from general medical practitioner to consultant otologist followed by clinical examination, audiological tests, and, if necessary, radiological and pathological diagnostic measures. For most patients treatment meant the issue of a hearing aid six weeks to three months after an impression for an insert ear mould had been taken. Finally, the patient attended a follow-up consultation with the otologist or his clinical assistants. Reports by Kodicek and Garrard (1954), Dickson (1968),
Bicknell and Davies (1968), and others confirmed the impressions gained from our own experience that the procedure for issuing aids leaves much to be desired.

Jensen and Finch (1968) record that $90 \%$ successful use of hearing aids can be obtained by the domiciliary visiting of audiologists. This method was also advocated by Wilkins (1948), Franson (1968), Jordan (1968), and by Ronholt (1968) who used volunteers. The factors for success were listed by Orwell (1968) and Ewing and Ewing (1967). These authors maintained that the essential conditions are assistance in adapting the patient to the use of the aid, the control of technical factors, and the use of correct speech to the patient.

To obtain such a service through official channels would be expensive and time consuming. The suggestion of voluntary visiting, used by Ronholt, seemed to offer the best chance of success in providing some necessary domiciliary training for the elderly deaf and for gaining experience not previously recorded in the organization, handling, and improvement of the service to this class of patient.

\section{Description of Service}

\section{RECRUITMENT}

A trained social worker was asked through the Council of Churches to act as recruiting officer for the voluntary visitors to the elderly deaf. She contacted various organizations for recruits, checked their qualifications, and interviewed them if necessary. They were given simple training in handling hearing aids and elementary instruction in the types of hearing disability 